\title{
Estimating Producers' Preferences for Sod Attributes: A Combined Approach of Discrete Choice Experiments and Eye-tracking Technology
}

\author{
Candi Ge \\ Institute of Agricultural Economics and Development, Jiangsu Academy of \\ Agricultural Sciences, Nanjing, Jiangsu 210014, China
}

Chanjin Chung

Department of Agricultural Economics, Oklahoma State University, Stillwater, OK 74078

\author{
Tracy A. Boyer \\ School of Freshwater Sciences, University of Wisconsin-Milwaukee, \\ Milwaukee, WI 53204
}

\section{Marco Palma \\ Department of Agricultural Economics, Texas A\&M University, College Station, TX 77843}

Additional index words. attribute non-attendance, discrete choice, scale change, sod producer, sod attributes, willingness-to-accept

\begin{abstract}
This study combines a discrete choice experiment and eye-tracking technology to investigate producers' preferences for sod attributes including winterkill reduction, shade tolerance, drought tolerance, salinity tolerance, and maintenance cost reduction. Our study results show that sod producers valued drought tolerance the most, followed by shade tolerance, winterkill reduction, salinity tolerance, and lastly, a $10 \%$ maintenance cost reduction. Choice survey data revealed the existence of attribute nonattendance, i.e., respondents skipped some attributes, but statistical tests detected no clear evidence about the role of individuals' attention changes on their willingness-toaccept estimates. Estimates using a scale heterogeneity multinomial logit model indicate an overall learning effect as respondents made choices in the survey. Producers' willingness-to-accept were generally higher than consumers' willingness-to-pay for the improved sod variety attributes, except for the drought tolerance attribute. However, the rankings for these attributes were the same between consumers and producers.
\end{abstract}

Sod turfgrass provides significant environmental benefits (Beard and Green, 1994; Stier et al., 2013). However, if improperly managed or used in drought-prone areas, sod causes detrimental environmental effects, such as high water consumption or excessive nutrient and pesticide runoff (Beard and Green, 1994; Stier et al., 2013). Consumers who prefer specific sod attributes maintain large swaths of irrigated and managed turf areas (Ghimire et al., 2016, 2019; Yue et al., 2017). To address some of the tough management issues and meet consumer demand, sod producers may seek to adopt new varie-

Received for publication 8 June 2020. Accepted for publication 16 July 2020.

Published online 20 August 2020.

This work was supported by the USDA Specialty Crop Research Initiative Award No. 2010-51181-21064.

C.C. is the corresponding author. E-mail: chanjin. chung@okstate.edu.

This is an open access article distributed under the CC BY-NC-ND license (https://creativecommons. org/licenses/by-nc-nd/4.0/). ties. Developing and marketing new lowinput sod varieties is one way to reduce the environmental effects of sod production and management by the public.

As the sod industry expands, producers and breeders face the challenge of producing new and improved varieties to meet consumer demand at reasonable prices (Chung et al., 2018). While prior studies identified household consumer preferences for sod varieties (Ghimire et al., 2016, 2019; Hugie et al., 2012; Yue et al., 2012, 2017), little information is available on what products sod producers believe they can market to consumers. Given that producers may only be able to grow and market limited varieties at a time, knowing what the producers perceive as valuable is also important for the development and ultimate adoption of improved sod varieties for the consumer market. Unlike previous studies that evaluate consumer (or homeowner) preferences, our study focuses on evaluating sod producers' preferences for biotic stress im- provements and maintenance reductions of new warm-season varieties.

Discrete choice experiments (DCEs) are widely used to help reveal how respondents value each attribute or characteristic of a product, in the form of a consumer's willingness-to-pay (WTP) or a producer's willingness-to-accept (WTA). To identify producers' preferences for sod attributes, we conduct a DCE in combination with the eye-tracking technology. The eye-trackers contribute real-time data for the individual's attendance and fixation to each attribute. In the theory of DCE, each respondent is assumed to evaluate and process all information provided during each choice task efficiently, thus making consistent choices with a constant degree of variability (Day et al., 2012; Hensher et al., 2005). The attribute non-attendance (ANA) problem arises when respondents do not pay attention to all attributes in all alternatives in the choice experiment. Previous studies confirmed the existence of ANA, which may lead to inconsistent decisions and biased preference estimates, typically represented by WTP or WTA (Hensher et al., 2005; Kragt, 2013).

The extent of eye-fixation could affect the likelihood of an alternative being chosen and therefore, estimates of respondents' preferences for product and service attributes (Behe et al., 2015; Bialkova et al., 2014; van der Laan et al., 2015), as well as the estimated WTP, in an unpredictable direction (Rihn and Yue, 2016). Respondents' eye-fixation may also reveal the learning and fatigue effects when they face multiple choice-tasks (Balcombe et al., 2015). When respondents learn across choice tasks, they make decisions that are more consistent and exhibit lower variances; when participants are fatigued or bored, their decisions are more inconsistent, thus exhibiting higher variances. By investigating the consistency of variance scales in the logit function, we can identify respondents' learning or fatigue effects.

The overall objective of this study is to estimate sod producers' preferences for warm-season sod attributes. We also demonstrate the importance of addressing the ANA problem and attentional changes using eyetracking data. Besides, we identify possible learning and fatigue effects by considering the effect of eye fixations. Finally, we discuss discrepancies between producers' WTA estimates and consumers' WTP estimates previously reported by Ghimire et al. (2019). Our study allows us to signal sod producers' preferences for production and sale of warm-season turf-varieties in sod firm (rather than seed). As the sod producer group is small and can be hard to reach, having information about their production preferences and how they evaluate different attributes compared with consumers is a significant contribution to the sod industry.

Our study results show that respondents ignore some of the attributes, as some respondents identified as visual non-attenders even ignored specific attribute(s) in more 
than half of the 12 choice tasks. Price was the most ignored attribute. Our respondents value drought tolerance the most, followed by shade tolerance, winterkill reduction, salinity tolerance, and lastly, a 10\% maintenance cost reduction. Based on the statistical tests, there was no clear evidence showing that respondents' preferences vary with their attention change, even though we identified an overall learning effect along sequential choices. We also found that in general, producers' WTAs were higher than consumers' WTPs for the improved sod attributes, except for the drought tolerance attribute. However, the rankings for all attributes were the same between consumers and sod producers, indicating that sod producers understand the consumer preferences of their household market to some extent.

\section{Literature Review}

Because of periodic and seasonal drought in areas growing warm-season grasses such as the mid-southern and eastern southern United States, low-input and resilient sod species are in high demand (Ghimire et al., 2016). Hugie et al. (2012) conducted an onsite study on consumers' preferences for lowinput sod and showed that lower irrigation and mowing requirements of certain sod species significantly affect consumers' purchasing behavior. Yue et al. (2012) implemented a web survey with homeowners and obtained similar results to Hugie et al. (2012). Ghimire et al. (2016)'s web-based survey investigated consumers' preferences for sod attributes in five southeastern and midsouthern states (including Florida, Georgia, North Carolina, Oklahoma, and Texas) and found that the three most-preferred sod attributes were low average maintenance cost, shade tolerance, and water conservation. In a study conducted in the United States and Canada, Yue et al. (2017) reported that consumer preferences were significantly affected by turfgrass attributes such as low maintenance cost and drought tolerance; thus concluding the existence of a large potential market for low-input sod species. Ghimire et al. (2019) assessed consumers' preferences for warm-season sod attributes and found that household sod consumers were willing to pay price premiums for reduced winterkill, reduced water requirements, salinity tolerance, shade tolerance, as well as lower maintenance costs. Ghimire et al. (2019) also revealed that when the price was lower, consumers were more willing to accept sod requiring higher maintenance costs.

Scarpa et al. (2009) stated that ANA seriously affected the derivation of welfare estimates, especially when money attributes are included. To address the ANA problem, previous studies asked survey participants to self-report whether they ignored specific attributes while taking the survey (Campbell, 2008; Hensher, 2008; Hensher and Rose, 2009). However, Balcombe et al. (2015) and Kragt (2013) argued that the stated nonattendance to an attribute cannot accurately represent the visual non-attendance. Because eye fixations well represent people's attention changes (Russo, 2011; Vidal et al., 2013), the use of eye-tracking devices can help to record respondents' eye movements during the survey, and thus reveal the existence of ANA (Chavez et al., 2018).

Including attention in conjoint analysis increases the explanatory power of the regression model (Bialkova et al., 2014). Eye movements can indicate respondents' preferences for attributes, as well as choices. Meißner and Decker (2010) found that fixations received by attributes or stimuli, as recorded by the eye-tracker, were positively correlated with attributes' importance. Behe et al. (2014), Rihn and Yue (2016), and Van Loo et al. (2015) also concluded that consumers were more likely to fixate on more important or valuable attributes. Behe et al. (2015), Bialkova et al. (2014), Krajbich et al. (2010), and van der Laan et al. (2015) indicated that the probability of a product being chosen increased with more and longer fixations. Rihn and Yue (2016) stated that including changes in attention on variables affected the WTP in an uncertain direction.

Our study fills several gaps in the literature estimating sod preferences. First, unlike many previous studies, our study attempts to identify the existence of ANA and to test if a change in respondents' attention during choice experiments could result in biased outcomes if changes are not properly considered in econometric models. Second, many previous studies focus on consumers, while ignoring how producers assess economic values of sod attributes. In this study, we survey sod producers to discuss between producers' preferences and consumers' preferences.

\section{Materials and Methods}

Econometric models. According to Balcombe et al. (2015), if a respondent has no more than two fixations to one attribute in a single choice task, the ANA problem exists; if respondents do not attend the attribute for at least half of the choice tasks, they are visual non-attenders. On the above basis, this study first examines the existence of ANA and visual non-attenders. To determine whether respondents' attention during choice experiments affects sod-producers' WTA estimates of sod attributes, we estimate conditional logit models (CLMs) including and excluding respondents' fixation, and we compare the obtained WTAs between the two models using multiple testing procedures. We also estimate a scale heterogeneity multinomial logit model (SHLM) to examine the effect of potential changes in variance scale caused by attention changes. Finally, we discuss the factors between sod-producers' WTAs and consumers' WTPs, estimated from Ghimire et al. (2019), for the same sets of sod attributes. CLM and SHLM have been estimated using SAS 9.4 and R 3.5.1, respectively.

Conditional logit model. The CLM focuses on respondents' choices on product attributes rather than individual characteristics. Then, an individual $i$ 's utility by choosing an alternative $j$ from choice set $k$ is formed by a deterministic component, $\boldsymbol{\beta} \mathbf{X}_{i j k}$, and a stochastic component, $\varepsilon_{i j k}$, as:

$$
U_{i j k}=\boldsymbol{\beta} \mathbf{X}_{i j k}+\boldsymbol{\varepsilon}_{i j k},
$$

where $\mathbf{X}$ is a vector of choice-specific variables, $\boldsymbol{\beta}$ is a corresponding vector of parameters, and $\varepsilon_{i j k}$ is an error component which has the iid Gumbel distribution. In the CLM, the unobservable scale parameter is set equal to $\frac{\pi^{2}}{6}$ to create a constant variance equal to one for all choice tasks. However, it is possible that the scale parameter varies across individuals and choice sets.

Scale heterogeneity multinomial logit model. To address the potential scale change, the iid assumption for the random term is relaxed to allow the scale to vary following a particular distribution (Czajkowski et al., 2014). Drawing on Fiebig et al. (2010), the utility function of a scale heterogeneity model is specified as

$$
U_{i j k}=\beta \mathrm{X}_{\mathrm{ijk}}+\frac{\varepsilon_{i j k}}{\sigma_{k}},
$$

where $\sigma_{k}$ is the scale parameter as a function of a vector of variables, which is defined as an exponential function as $\sigma_{k}=\exp (\bar{\sigma}+\varphi \mathrm{V})$, while $\bar{\sigma}, \mathrm{V}$, and $\varphi$ are the intercept of scale function, a vector of scale-related variables, and the vector of corresponding parameters, respectively. Because our study focuses on change in individuals' attention during experiments, we specify the scale parameter as a function of change in eye fixations as

$$
\sigma_{k}=\exp \left(\bar{\sigma}+\varphi v_{k}\right),
$$

where $v_{k}$ is the specified fixation measurement in the $k$ th choice task. If the parameter $\varphi$ equals zero, we conclude no scale change; thus no learning or fatigue effect is present. If $\varphi$ is positive and significant, the larger the fixation variable is, the smaller the error variance is; thus an increasing fixation variable across choice tasks indicates the existence of a learning effect, while a decreasing fixation variable indicates the fatigue effect. If $\varphi$ is negative and significant, the larger the fixation variable is, the larger the error variance is; thus an increasing fixation variable confirms the existence of a fatigue effect, while a decreasing fixation variable confirms the learning effect.

Discrete choice experiment. For the experimental design we started with 48 possible choice sets, divided into four blocks, and we used a fractional factorial design procedure to generate 12 choice tasks with a $98.5 \%$ Defficiency with no priors. When presented to respondents, the orders of the choice tasks were randomized to eliminate starting-point effect. Even though randomization of choice sets addresses a problem of potentially violating iid assumption caused by choice set design, the potential violation of iid assumption due to a respondent's attention changes during the experiment could still be problematic. Each choice task contains three alternatives: two "product purchase" options and one "no-purchase" option. The two purchase 
options each described a sod product with at least one of the valued attributes and a respective price. In consultation with a horticulture expert and professor at Oklahoma State University, and using estimates provided by two sod producers for farm gate prices in Kansas and Oklahoma, we determined the upper and lower bounds of the price attribute for warm-season sod. The prices presented to respondents varied at one of the four levels: $\$ 0.15 / \mathrm{ft}^{2}, \$ 0.25 / \mathrm{ft}^{2}$, $\$ 0.45 / \mathrm{ft}^{2}$, and $\$ 0.55 / \mathrm{ft}^{2}$. Producers were asked to consider, "Options A and B represent two different sets of sod/sod bermuda or zoysia marketing characteristics and reductions in buyers' maintenance such as weed control, mowing, and fertilizer. Which option (A, B, or C) would you be most likely to produce to market to consumers?" Figure 1 presents a sample choice task as seen by respondents. To discuss factors between sod producers and consumers, our study focuses on the same set of attributes as in Ghimire et al. (2016, 2019): winterkill reduction, shade tolerance, drought tolerance, salinity tolerance, and maintenance cost reduction. Winterkill occurs when sod suffers irreversible damage due to low temperatures (Dionne et al., 2001; Trenholm, 2000). Because photosynthesis requires sunlight, the decrease in light intensity due to shade can reduce the quality of sod. Warm-season sod, in general, is less shade-tolerant than cool-season sod (Moss et al., 2009; Patton, 2008). The high amount of water usage from sod irrigation, particularly under restricted water usage, increases the need for drought-tolerant sod (Leksungnoen et al., 2012; Zhao et al., 1994). When the use of freshwater is restricted, groundwater is often in use for irrigation as an alternative water source. However, the high soluble salt levels in groundwater may cause salinity stress to grasses. Swift and Koski (2007) show that high salt levels in water may cause grass to suffer from root damage and increase drought kill. Finally, maintenance cost and price are also considered as important factors that can affect consumer choice of sod varieties (Ghimire et al., 2016, 2019; Yue et al., 2017).

Respondents in our sample were warmseason sod producers recruited in person at the Turfgrass Producers International Conference (TPIC) in San Diego, CA, in 2015. Collecting data in person is preferred because of eye-tracking technology, and the conference venue made recruitment easier and more complete compared with methods such as email recruitment. The recruited respondents were asked to take the choice experiments with eye-tracking devices installed in the conference booth and information area. Participants first completed the demographic information on a tablet and subsequently proceeded to the two working stations with computers hooked up to eye-tracking devices. Participants were asked to sit comfortably and aligned with the monitor of the eye tracker, with a nine-point calibration first conducted to ensure proper eye-tracking metrics. Participants then responded to the choice tasks and received a compensation fee of $\$ 30$ at the end of the experiment. To obtain more precise eye measurements from respondents, we used two Tobii TX $300 \mathrm{~Hz}$ devices. These are one of the highest resolution devices capable of recording at $0.4^{\circ}$ accuracy (binocular) and $0.15^{\circ}$ precision (unfiltered). We used the TX 300 mounted 23 in. screen (Tobii screen attached to the eye tracker) at a resolution of $1920 \times 1080$ pixels and a nine-point calibration. The ranges in fixation counts for each attribute were very large. For example, the numbers of fixations for the box corresponding to the winterkill reduction, shade tolerance, drought tolerance, salinity tolerance, $10 \%$ maintenance cost reduction, and price ranged between $0-24,0-30,0-24,0$ $29,0-17$, and $0-14$, respectively. Fixation ranges provide an indication that the highresolution Tobii device is capturing differences in our specified areas of interest even though they are relatively small.

Due to the long duration of the experiment (mostly between forty-five minutes and an hour) and the limited number of producers

\begin{tabular}{|c|c|c|c|}
\hline Attributes & Option A & Option B & Option C \\
\cline { 1 - 3 } Winterkill Reduction & YES & NO & If A or B were the only \\
available options, I \\
Shade Tolerance & YES & NO & \multirow{2}{*}{ would NOT produce } \\
Drought Tolerance & YES & NO for my facility. \\
\hline Salinity Tolerance & NO & YES & \\
\cline { 1 - 2 } $10 \%$ Maintenance Cost Reduction & YES & NO & \\
\hline Farm gate Price per Square Foot & $\$ 0.15$ & $\$ 0.25$ & \\
\hline I would choose & $\square$ & $\square$ & \\
\hline
\end{tabular}

Fig. 1. Example of a choice task shown to producers. Options A and B represent two different sets of sod/ sod Bermuda or zoysia marketing characteristics and reductions in buyers' maintenance such as weed control, mowing, and fertilizer. Which option (A, B, or C) would you be most likely to produce to market to consumers?

who produced warm-season sod among conference participants, we have a relatively small sample size. In total, 32 subjects participated in our survey. Four subjects' data were missing eye-tracking information because we were unable to calibrate the device to their eyes. Thus, the usable data are from 28 subjects with 12 choice sets for each subject, adding up to a total sample size of 336 .

Our sample has 21 female participants and seven male participants. Producers who attended the TPIC at their own expense tend to be the more innovative producers and may indeed include more females who manage and direct sod farms and family businesses. The average age of our participants was around 48 years, ranging from 26 to 76 years old. Nine participants had attended some college, while 17 participants had earned a bachelor's degree or higher. Six of our respondents majored in sod management or plant and soil science, and the rest majored in other subject areas. Our respondents were mainly from South Carolina (22.2\%), Illinois (14.8\%), Oklahoma (14.8\%), Texas (14.8\%), and North Carolina (11.1\%). The major grass types they produce are bermuda grass $(41.9 \%)$, tall fescue $(22.7 \%)$, St. augustine $(14.4 \%)$, and zoysia $(13.6 \%)$. Our respondents' total production area represented 50,075 acres, which accounted for about $15 \%$ of sod production area nationwide (USDA-NASS, 2019). Two of them had larger than 10,000 acres of production area, while five others had production areas between 1000 and 10,000 acres. The rest of the producers had less than 1,000 acres in production. Based on the categories of 2017 Census of Agriculture (USDA-NASS, 2019), most respondents are larger-scale sod producers with a production area larger than 399 acres. Because we recruited our respondents at a networking and research conference, the sample may include more innovative sod producers. Even though our sample may be biased in terms of which producers attended the conference, the larger-scale, more innovative sod producers are more likely to adopt, produce, and sell more newly developed cultivars at premium prices. The top three largest buyers of our respondents' sod were landscape services, commercial or residential developers, and golf courses. The respondents' total annual sales in 2014 added up to $\$ 254$ million, with average sales of $\$ 9$ million per producer. Warm-season sod sales in Oklahoma, Texas, North Carolina, Georgia, and Florida in 2015 were about $\$ 109$ million (Chung et al., 2018). Comparing the 2017 sales amount (USDANASS, 2019), our sample counts for more than $22 \%$ of the sod value in the United States. Thus, our sample is likely to encompass a large proportion of the U.S. market. Sod producer data were collected contemporaneously with information on sod consumer preferences, allowing for a unique insights and comparisons between producer and consumer preferences.

\section{Results and Discussion}

Unattended attributes. Figure 2 illustrates respondents' non-attendance to attributes. 

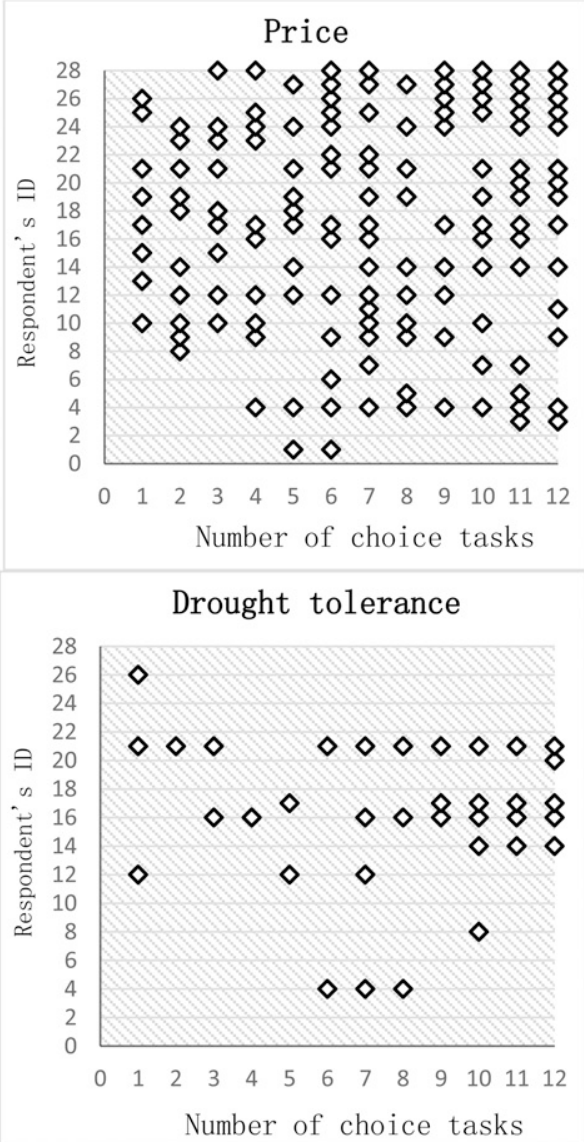
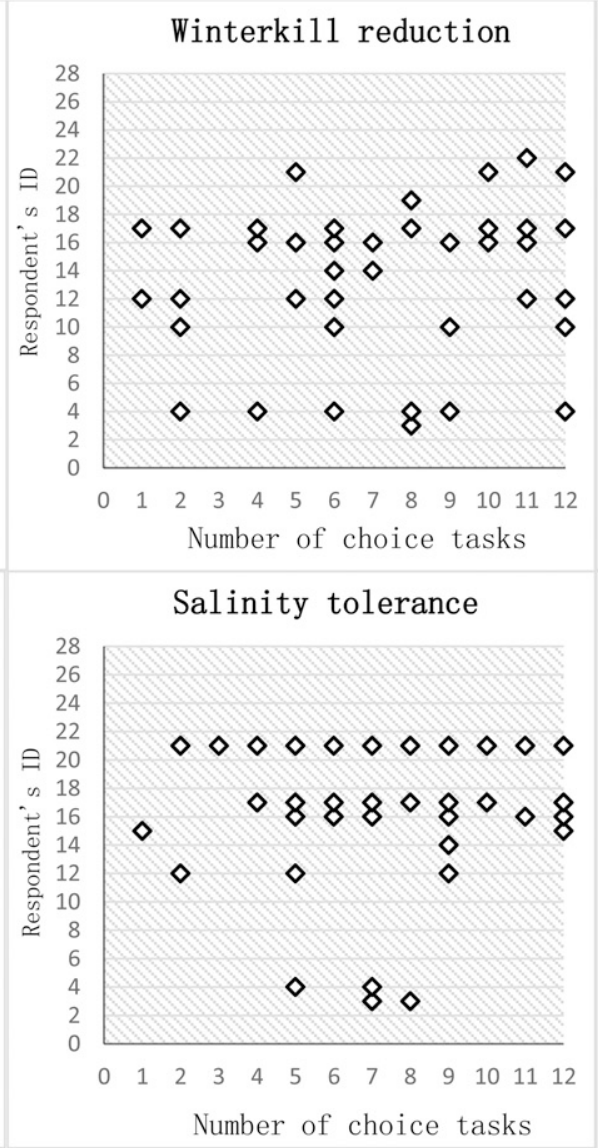

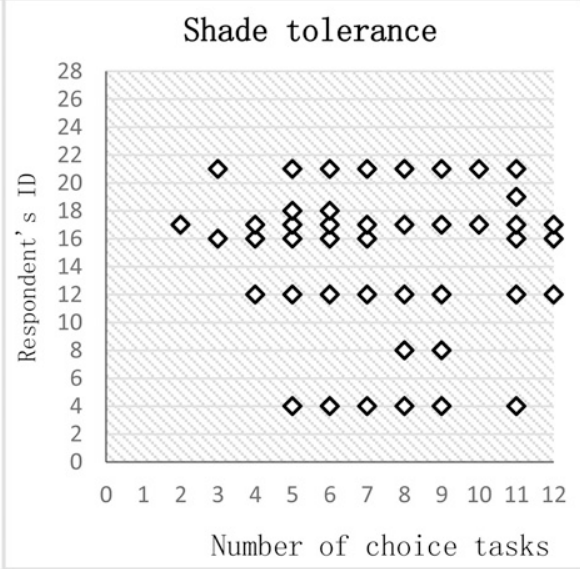

$10 \%$ Maintenance cost

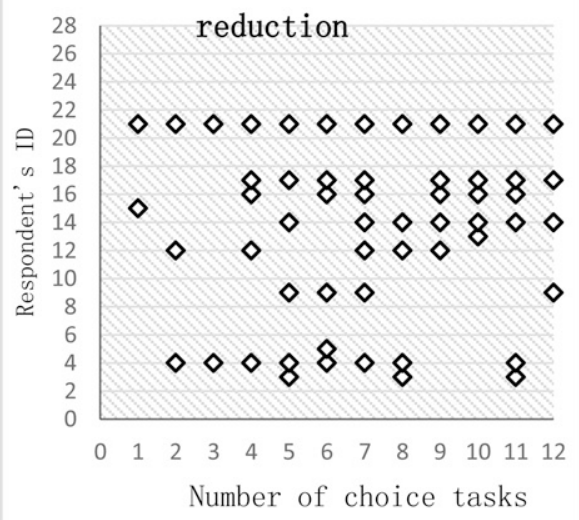

Note: the diamond for each choice task indicates non-attendance by respondents.

Fig. 2. Respondents' attribute non-attendance by attribute. The diamond for each choice task indicates non-attendance by respondents.

Table 1. Pairwise comparison of the proportional total visit duration (PTVD) for the first two choice tasks using the Friedman test ( $\mathrm{n}=336$ ).

\begin{tabular}{|c|c|c|c|c|c|c|c|}
\hline Choice sets & Mean difference & Test statistic & Adjusted $P$ value & Choice sets & Mean difference & Test statistic & Adjusted $P$ value \\
\hline 1 vs. 4 & 8.214 & 11.760 & 0.000 & 2 vs. 4 & 3.291 & 4.710 & 0.000 \\
\hline 1 vs. 5 & 8.999 & 12.880 & 0.000 & 2 vs. 5 & 4.076 & 5.830 & 0.000 \\
\hline 1 vs. 7 & 8.759 & 12.540 & 0.000 & 2 vs. 7 & 3.835 & 5.490 & 0.000 \\
\hline 1 vs. 8 & 10.247 & 14.670 & 0.000 & 2 vs. 8 & 5.324 & 7.620 & 0.000 \\
\hline 1 vs. 9 & 10.016 & 14.340 & 0.000 & 2 vs. 9 & 5.093 & 7.290 & 0.000 \\
\hline 1 vs. 12 & 9.962 & 14.260 & 0.000 & 2 vs. 12 & 5.038 & 7.210 & 0.000 \\
\hline
\end{tabular}

${ }^{\mathrm{z}}$ Adjusted $P$ values were calculated while considering tied values in the sample.

For each attribute, a diamond assigned to one choice set indicates that the respondent passed over or "non-attended" the attribute. Eleven respondents attended to all attributes except for price in all choice tasks, while the rest (17 respondents) ignored at least one sod attribute in one choice set. Only one respondent fully attended to all six stimuli including the price. Respondent 16 is a visual non-attender of all attributes. Among all stimuli, drought tolerance is the attribute with the least visual-non-attenders, while price is the one with the most visual-nonattenders. Thirteen respondents are visual non-attenders for the price stimulus. We claim the existence of ANA in our choice experiment data.
Visual data analysis. For each area of interest (AOI), four measurements were recorded, including time to first fixation, total fixation duration, fixation counts, and total visit duration. Time to first fixation is the length of the time that a respondent first fixates on an AOI. Total fixation duration is the entire length of time that a respondent fixates on one AOI. Fixation count is the number of times that a respondent fixates on an AOI. Total visit duration is the entire length of time that a respondent visits one AOI. Behe et al. (2015) stated that total visit duration is the most influential predictor of product choice. To control for individuals' different reading habits, the proportion of total visit duration (PTVD) for each choice task among all choice tasks was included as the fixation measurement variable in regression, i.e., $\mathrm{PTVD}=\frac{\text { total visit duration }_{k}}{\sum_{n=1}^{12} \text { total visit duration }_{n}}$, where $k$ and $n$ indicate the number of choice tasks.

Table 1 presents the pairwise-comparison results of PTVD for the first two choice sets ( 1 and 2) with each of the remaining choice tasks. We compare mean differences using the Friedman's test because PTVD data in our subsamples neither follow normal distributions nor have equal within-group variances. Therefore, standard parametric tests may not be appropriate to test for differences in PTVD between choice sets. We thus conduct the Friedman's test, which first ranks the 


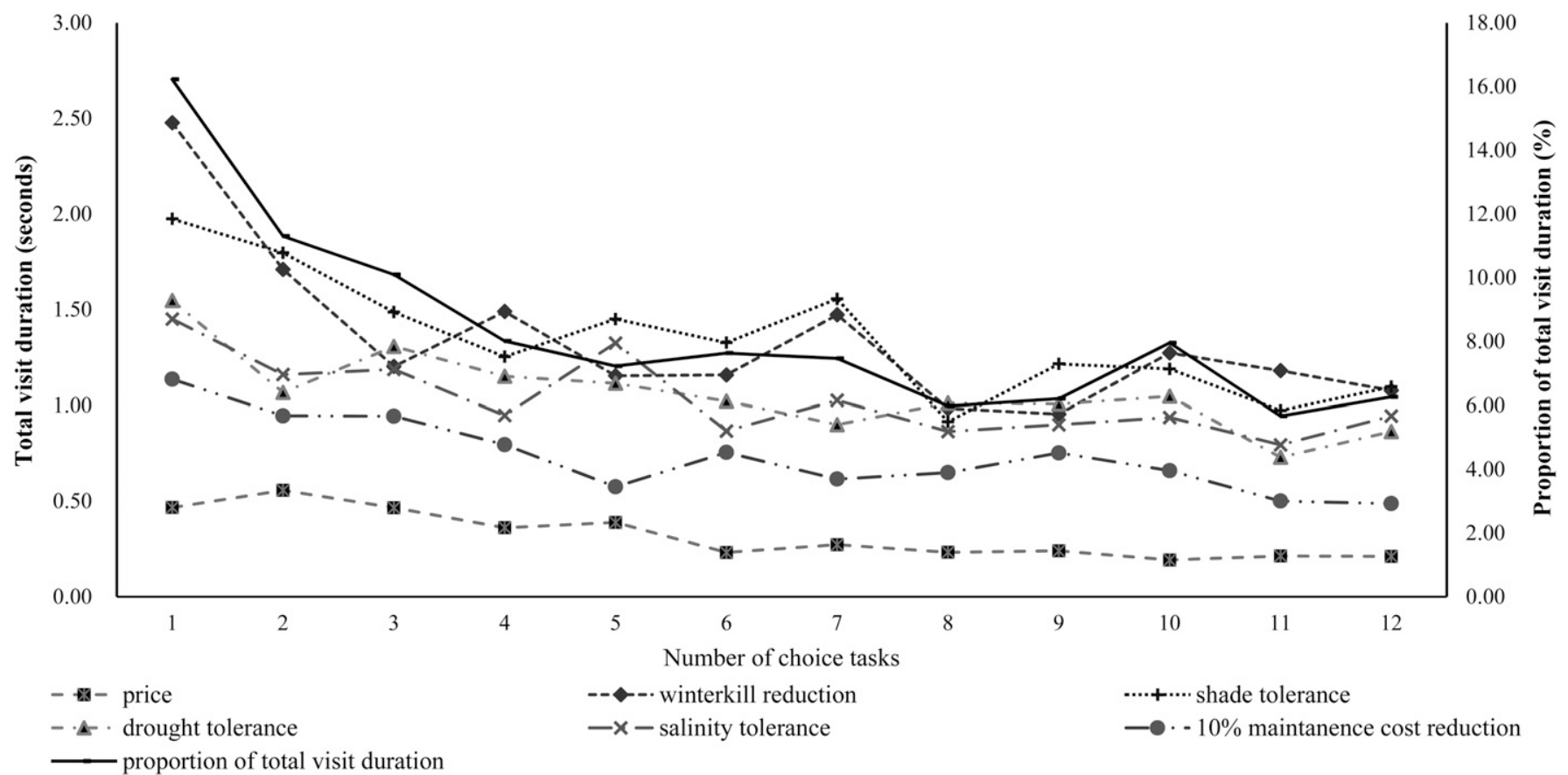

Fig. 3. Change in respondents' total visit duration for product attributes by sequentially numbered choice task.

Table 2. Estimates of the conditional logit (CLM) and scale heterogeneity multinomial logit (SHLM) models.

\begin{tabular}{|c|c|c|c|}
\hline Variable & $\begin{array}{l}\text { CLM without ANA or } \\
\text { eye-fixation variable }(I)^{z}\end{array}$ & $\begin{array}{l}\text { CLM with eye-fixation } \\
\text { variable (II) }\end{array}$ & $\begin{array}{c}\text { SHLM with eye-fixation } \\
\text { variable (III) }\end{array}$ \\
\hline Winterkill reduction & $0.626 * * *(0.090)[0.31]^{*}$ & $0.511 *(0.194)[0.32]^{*}$ & $0.950 * *(0.344)[0.31]^{*}$ \\
\hline Salinity tolerance & $0.458 * * *(0.084)[0.23]^{*}$ & $0.556^{* *}(0.181)[0.24]^{*}$ & $0.699 * *(0.242)[0.23]^{*}$ \\
\hline $10 \%$ Maintenance cost reduction & $0.402 * * *(0.089)[0.20] *$ & $0.501 *(0.182)[0.20]^{*}$ & $0.640 *(0.303)[0.21]^{*}$ \\
\hline Shade tolerance $\times$ PTVD & - & $-0.043(0.022)$ & - \\
\hline Drought tolerance $\times$ PTVD & - & $-0.062 *(0.021)$ & - \\
\hline Salinity tolerance $\times$ PTVD & - & $-0.011(0.020)$ & - \\
\hline $10 \%$ Maintenance cost reduction $\times$ PTVD & - & $-0.013(0.018)$ & - \\
\hline Scale term, intercept, $\bar{\sigma}$ & - & - & $0.222(0.670)$ \\
\hline Scale term fixation, $v$ & - & - & $-0.057 *(0.033)$ \\
\hline$-2 \log$ likelihood & 501.204 & 491.033 & 490.440 \\
\hline
\end{tabular}

${ }^{\mathrm{z}}$ Numbers in parentheses and brackets are standard errors and willingness-to-accept, respectively.

$*, * *,{ }^{* * *}$ Significant at $P \leq 0.05,0.01$, or 0.001 , respectively.

values of each matched set and then tests whether the rank totals for subsamples differ significantly (Dulce et al., 2015). Because choices in the first task might be more inconsistent compared with other choice tasks (Campbell et al., 2015), we also compared task 2 with the rest of the choice tasks. Table 1 shows that there is an overall decreasing trend of PTVD as respondents move toward later choice tasks, as well as a larger variability in PTVD between choice task 1 and the rest of the choice tasks. The fact that respondents pay more attention to the first choice task is likely a learning effect as respondents move through tasks. Figure 3 confirms that there is an overall decreasing trend in total visit duration as well as the proportion of total visit duration from the first choice task to the last choice task. Total fixation duration and fixation counts also show a similar decreasing trend.

Estimation results. Table 2 reports estimated parameters and corresponding WTAs from three regression models: CLM without eye-fixation variables (I), CLM with eyefixation variables (II), and SHLM with an eye-fixation variable (III). [Referring to Lagarde (2013), we attempted to include "ANA $\times$ attribute" interaction terms in the regression to distinguish between the attribute irrelevance and ANA, as well as detecting the effect of ANA on respondents' WTAs. Results show that when ANA is present, the estimated coefficients are not significantly different with their counterparts when ANA is absent, indicating that respondents ignored some attributes because of ANA instead of irrelevance. Fur- thermore, including ANA in the regression does not statistically change respondents' WTA estimates. Thus, we still exclude the ANA variables for the following regressions.] From Model I, the price coefficient is positive and significant at the 5\% level, implying that producers prefer to market sod products that are more expensive. The estimated coefficients of all sod attributes are positive as expected and significant at the $5 \%$ level, indicating that producers prefer to sell sod products with improved attributes. From Model I, producers' WTA for an attribute is calculated as the attribute coefficient divided by the price coefficient. All WTA estimates from Model I are significant at the 5\% level. Results show that sod producers value drought tolerance the most $\left(\$ 0.42 / \mathrm{ft}^{2}\right)$, 
Table 3. Willingness-to-accept comparisons between models.

\begin{tabular}{|c|c|c|c|c|c|}
\hline & Winterkill reduction & Shade tolerance & Drought tolerance & Salinity tolerance & $10 \%$ Maintenance cost reduction \\
\hline \multicolumn{6}{|c|}{ The Kruskal-Wallis rank sum test ( $P$ values $)$} \\
\hline Model II vs. Model I & $0.008 * *$ & $0.000 * * *$ & $0.022 *$ & $0.000 * * *$ & 0.404 \\
\hline Model III vs. Model I & $0.000 * * *$ & 0.465 & $0.034 *$ & $0.000 * * *$ & $0.002 * *$ \\
\hline \multicolumn{6}{|c|}{$95 \%$ Confidence interval of differences } \\
\hline Model II vs. Model I & $(-0.24,0.26)$ & $(-0.29,0.33)$ & $(-0.32,0.35)$ & $(-0.18,0.21)$ & $(-0.16,0.16)$ \\
\hline Model III vs. Model I & $(-0.27,0.22)$ & $(-0.32,0.35)$ & $(-0.37,0.33)$ & $(-0.22,0.18)$ & $(-0.19,0.17)$ \\
\hline \multicolumn{6}{|c|}{ Complete computational resampling approach ( $P$ values $)$} \\
\hline Model II vs. Model I & 0.999 & 0.959 & 0.995 & 0.958 & 1.000 \\
\hline Model III vs. Model I & 0.814 & 1.020 & 1.061 & 0.858 & 1.005 \\
\hline
\end{tabular}

$*, * *, * * *$ Significant at $P \leq 0.05,0.01$, or 0.001 , respectively.

followed by shade tolerance $\left(\$ 0.38 / \mathrm{ft}^{2}\right)$, winterkill reduction $\left(\$ 0.31 / \mathrm{ft}^{2}\right)$, salinity tolerance $\left(\$ 0.23 / \mathrm{ft}^{2}\right)$, and $10 \%$ maintenance cost reduction $\left(\$ 0.20 / \mathrm{ft}^{2}\right)$.

To consider the effects of a change in an individual's attention on choice or preferences (Van Loo et al., 2015), Model II extends Model I by incorporating the PTVD $\times$ attribute interaction terms. Compared with Model I, Model II does not improve model performance at the $5 \%$ level $(P=0.118)$. Estimation results reveal the same signs and significance levels for all coefficients. Producers' WTA of each attribute is calculated as

$$
\frac{\beta_{\text {attribute }_{t}}+\beta_{\text {attribute }_{t} \times P T V D} \overline{P T V D}}{\beta_{\text {price }}+\beta_{\text {price } \times P T V D^{P T V D}} \bar{P}},
$$

where $\beta_{\text {attribute }_{x} \times \text { PTVD }}$ is the estimated parameter of the interaction term between the $t$ th attribute and PTVD, $\beta_{\text {price } \times \text { PTVD }}$ is the estimated parameter of the interaction term between price and PTVD, and $\overline{P T V D}$ is the mean of PTVD from 12 choice tasks. The ranking of attributes from Model II stays the same with that in Model I, with drought tolerance as the highest $\left(\$ 0.42 / \mathrm{ft}^{2}\right)$, followed by shade tolerance $\left(\$ 0.39 / \mathrm{ft}^{2}\right)$, winterkill reduction $\left(\$ 0.32 / \mathrm{ft}^{2}\right)$, salinity tolerance $\left(\$ 0.24 / \mathrm{ft}^{2}\right)$, and $10 \%$ maintenance cost reduction $\left(\$ 0.20 / \mathrm{ft}^{2}\right)$. Coefficients of all interaction terms are insignificant, except for the "PTVD $\times$ drought tolerance" variable. The negative coefficient of the "PTVD $\times$ drought tolerance" interaction term indicates that an individual's longer attention in one specific choice task would lower the value of the drought tolerance attribute in that task. As our respondents are sod producers who know the industry well, the longer time they spend in one choice task reveals that they take more time to consider the attributes and price combination, and that they are not quite confident about their choice. Krajbich et al. (2010) indicate that more-difficult decisions usually take respondents more time. In this case, they may lower their WTA to match the attributes and price combinations. While producers' WTA for drought tolerance is the highest among all five attributes, it is probable that producers would lower the value of drought tolerance. However, this may be an empirical conclusion from our study.

Model III extends Model I by allowing scale to vary as individuals' attention level changes by choice task. The log-likelihood ratio test confirms that Model III is superior to Model I at the $5 \%$ level $(P=0.013)$. The estimated coefficients of the price and sod attributes are all positive and significant at the $5 \%$ level. The ranking of attributes remains the same as in previous models, with drought tolerance as the highest $\left(0.44 / \mathrm{ft}^{2}\right)$, followed by shade tolerance $\left(\$ 0.39 / \mathrm{ft}^{2}\right)$, winterkill reduction $\left(\$ 0.31 / \mathrm{ft}^{2}\right)$, salinity tolerance $\left(0.23 / \mathrm{ft}^{2}\right)$, and $10 \%$ maintenance cost reduction $\left(\$ 0.21 / \mathrm{ft}^{2}\right)$. The intercept for the scale function is positive but insignificant. According to the negative sign of the fixation-related scale term and decreasing trend of PTVD in Table 1 (taking Choice 2 as the base task), we identify that respondents paid identical attention between choices 2 and 3 , and then less attention all the way to Choice 12. Consistent with previous literature (Czajkowski et al., 2014), the results indicate an overall learning effect in this study.

Statistical tests of WTA between models. As the simulated WTAs do not satisfy normality and homogeneity of variance assumptions for the parametric tests, we conducted three nonparametric tests to investigate the preference change by comparing WTAs from Models II and III with that from Model I: Kruskal-Wallis one-way rank sum test, the confidence interval of differences, and the complete computational resampling approach. We generated 1000 data sets for each model based on estimates and their variance and covariance matrices using a Monte Carlo simulation procedure. The Kruskal-Wallis rank sum test is a one-way analysis of variance approach that tests whether two samples originate from the same distribution or not. For the confidence interval approach, first, differences in WTAs are calculated between all possible one million combinations (1000 $\times 1000$ ) from two models in comparison. (As WTA is a monetary value, we rounded all numbers to two decimals so that the smallest unit of WTA is in one cent.) Then, the $2.5 \%$ and $97.5 \%$ percentiles of the calculated one million differences are used to obtain the $95 \%$ confidence interval. For the complete computational resampling approach, we order the WTA differences calculated from the one million pairs (used for the confidence interval approach) and calculate the proportion of differences that are less than and equal to zero among all pairs. Then, the $P$ value of the two-sided test is computed by doubling the proportion of differences that are less than and equal to zero. Therefore, the null hypothesis of equality is rejected at the $5 \%$ level if the $P$ value of the two-sided test is smaller than 0.05 (Poe et al., 2005).

Table 3 summarizes results of the three nonparametric tests. The Kruskal-Wallis rank sum test identifies differences in WTAs between models. When including the fixation variables as interaction variables, the estimated WTAs for winterkill reduction, shade tolerance, drought tolerance, and salinity tolerance show significant differences between Models I and II. The calculated WTA for $10 \%$ maintenance cost reduction from Model II is not statistically different from its counterpart from Model I. The WTAs for all attributes except for shade tolerance differ between Model III and Model I at the 5\% level. Results from the other two tests $(95 \%$ confidence interval and complete computational resampling tests) indicate no statistical differences in estimated WTAs between Models II/III and Model I at the 5\% level. The three tests used in this study show mixed results, an outcome that provides no clear evidence about the role of individuals' attention change on their preferences during a choice experiment. A possible reason is that our respondents are sod producers who are quite knowledgeable on sod attributes and the overall industry, and thus their preferences for sod attributes might be relatively stable under different choice environments.

Discussion of sod producers' WTA and consumers' WTP. Ghimire et al. (2019) stated that consumers are willing to pay the highest premium for drought tolerance $\left(\$ 0.45 / \mathrm{ft}^{2}\right.$ to $\left.\$ 0.86 / \mathrm{ft}^{2}\right)$, followed by winterkill reduction $\left(\$ 0.18 / \mathrm{ft}^{2}\right.$ to $\left.\$ 0.39 / \mathrm{ft}^{2}\right)$, shade tolerance $\left(\$ 0.33 / \mathrm{ft}^{2}\right)$, maintenance cost reduction $\left(-\$ 0.26 / \mathrm{ft}^{2}\right.$ to $\left.\$ 0.08 / \mathrm{ft}^{2}\right)$, and salinity tolerance $\left(\$ 0.03 / \mathrm{ft}^{2}\right)$. Producers' WTA of winterkill reduction is between the ranges of consumers' WTP, which is slightly lower than consumers' maximum WTP. Producers expect slightly higher price premiums from providing the shade tolerance attribute than consumers are willing to pay, as consumers' WTP is lower than producers' WTA. Producers' WTA of drought tolerance is even below the lowest level of consumers' WTP, indicating that producers may be able to receive higher price for providing the drought tolerance attribute to consumers in the five states. Producers expect higher prices than consumers' WTP for providing the salinity tolerance and maintenance cost 
reduction attributes. Estimates from the two studies indicate considerable differences between consumer WTPs and producer WTAs. In general, producers' WTAs are higher than consumers' WTPs for the improved sod attributes except for drought tolerance, but the rankings for these attributes are the same between consumers and producers.

There might be two possible reasons for the divergence between producers' WTA and consumers' WTP. First, producers may have not updated themselves with consumers' preferences for new sod attributes. In other words, they may have not realized turf consumers' real preferences. Second, producers know consumers' preferences, but there may be limitations in providing sod with improved attributes that consumers want. The current grass species may not meet consumers' demands, and/or the cost of providing grass species with improved attributes could be too high.

\section{Conclusions}

This study estimates sod producers' preferences for attributes of warm-season sod. Our study combines the eye-tracking technology and conjoint analysis to investigate the importance of addressing respondents' attention in estimating producers' preferences for sod attributes. We also discuss the factors between producers' preferences and consumers' preference estimates from a published study for the same set of attributes of improved warm-season varieties.

Our study confirmed the existence of ANA and visual non-attenders. All respondents except one ignored at least one product attribute, while price is the most ignored attribute. Respondents value drought tolerance the most, followed by shade tolerance, winterkill reduction, salinity tolerance, and lastly, a $10 \%$ maintenance cost reduction. Three tests, the Kruskal-Wallis one-way rank sum test, the confidence interval of differences, and the complete computational resampling approach, were conducted to compare estimates between different logit models. Based on the results, we claim no clear evidence that individuals' attention change affects their WTA estimates. An overall learning effect was identified from earlier choices to later choices. Comparing producers' and consumers' preference estimates, we found that producers' WTAs were higher than consumers' WTPs for all improved sod attributes except for drought tolerance, but the rankings for attributes were identical between consumers and producers.

This study contributes to the discrete choice experiment research by considering respondents' attention in logit regressions. The study evaluates the effect of controlling respondents' attention change in regression models on sod preference estimates. We also contribute to the horticulture literature by comparing producers' preferences to consumers' preferences for the same set of sod attributes. Understanding divergence between producer and consumer preferences for sod attributes should be important for developing marketing and research strategies for the sod industry. To the best of our knowledge, no previous research has dealt with these two important issues for the sod industry.

One limitation of this study is its relatively small sample size. Most studies with tracking data such as eye fixation and MRI record data tend to have small sample sizes because of the longer time and higher cost required for data collection. Our experiment length was restricted to the conference period, and a small target sample of warmseason producers. While we had two eyetracking devices installed, finishing one complete sample necessitated about $45 \mathrm{~min}$ to an hour, which may have discouraged more participation despite a $\$ 30$ incentive for the participants' time. One caveat is that these data may not reflect the current preferences and market environment for sod producers, thus results and recommendations should be viewed in this light. Our study also used hypothetical scenarios that did not require respondents to adopt and breed the product presented to them. The sod producer experiments are estimated using hypothetical scenarios because the improved cultivar with the given attributes posed have yet to be developed. In addition, the hypothetical nature may have caused the respondents to act slightly different from what they would do in the real world. However, the consumers' WTPs from Ghimire et al. (2019) are also estimated under hypothetical scenarios for the same hypothetical attribute improvements. Therefore, our findings about differences between producers' WTA and consumers' WTPs are comparable. Our study gives the first insight on the benefits of combining eye fixation with the conjoint analysis for the sod industry. Future research could expand the sample size with wider ranges of demographic characteristics and explore various approaches, for example, cheap talk, data screening, calibration, and real money commitment, to reduce the hypothetical bias problem.

\section{Literature Cited}

Balcombe, K., I. Fraser, and E. McSorley. 2015. Visual attention and attribute attendance in multi-attribute choice experiments. J. Appl. Econ. 30:447-467.

Beard, J.B. and R.L. Green. 1994. The role of turfgrasses in environmental protection and their benefits to humans. J. Environ. Qual. 23:452-460.

Behe, B.K., M. Bae, P.T. Huddleston, and L. Sage. 2015. The effect of involvement on visual attention and product choice. J. Retailing Consum. Serv. 24:10-21.

Behe, B.K., B.L. Campbell, H. Khachatryan, C.R. Hall, J.H. Dennis, P.T. Huddleston, and R.T. Fernandez. 2014. Incorporating eye tracking technology and conjoint analysis to better understand the green industry consumer. HortScience 49:1550-1557.

Bialkova, S., K.G. Grunert, H.J. Juhl, G. WasowiczKirylo, M. Stysko-Kunkowska, and H.C. van Trijp. 2014. Attention mediates the effect of nutrition label information on consumers' choice. Evidence from a choice experiment involving eye-tracking. Appetite 76:66-75.

Campbell, D. 2008. Identification and analysis of discontinuous preferences in discrete choice experiments. European Assn. of Environ. and Resource Economists Annu. Conf. Gothenburg, Sweden, 25-28 June 2008.

Campbell, D., M. Boeri, E. Doherty, and W.G. Hutchinson. 2015. Learning, fatigue and preference formation in discrete choice experiments. J. Econ. Behav. Organ. 119:345-363.

Chavez, D., M. Palma, and A. Collart. 2018. Using eye-tracking to model attribute non-attendance in choice experiments. Appl. Econ. Lett. 25:1355-1359.

Chung, C., T.A. Boyer, M. Palma, and M. Ghimire. 2018. Economic impact of drought- and shadetolerant Bermudagrass varieties. HortTechnology 28:66-73.

Czajkowski, M., M. Giergiczny, and W.H. Greene. 2014. Learning and fatigue effects revisited: Investigating the effects of accounting for unobservable preference and scale heterogeneity. Land Econ. 90:324-351.

Day, B., I.J. Bateman, R.T. Carson, D. Dupont, J.J. Louviere, S. Morimoto, R. Scarpa, and P. Wang. 2012. Ordering effects and choice set awareness in repeat-response stated preference studies. J. Environ. Econ. Mgt. 63:73-91.

Dionne, J., Y. Castonguay, P. Nadeau, and Y. Desjardins. 2001. Freezing tolerance and carbohydrate changes during cold acclimation of green-type annual bluegrass (Роа аппиа L.) ecotypes. Crop Sci. 41:443-451.

Dulce, G.P., A. Afonso, and F.M. Medeiros. 2015. Overview of Friedman's test and post-hoc analysis. Commun. Stat. Simul. Comput. 44(10):2636-2653

Fiebig, D.G., M.P. Keane, J. Louviere, and N. Wasi. 2010. The generalized multinomial logit model: Accounting for scale and coefficient heterogeneity. Mktg. Sci. 29:393-421.

Ghimire, M., T.A. Boyer, C. Chung, and J.Q. Moss. 2016. Consumers' shares of preferences for turfgrass attributes using a discrete choice experiment and the best-worst method. HortScience 51:892-898.

Ghimire, M., T.A. Boyer, and C. Chung. 2019. Heterogeneity in urban consumer preferences for turfgrass attributes. Urban For. Urban Green. 38:183-192.

Hensher, D.A. 2008. Joint estimation of process and outcome in choice experiments and implications for willingness to pay. J. Transp. Econ. Policy 42:297-322.

Hensher, D.A., J. Rose, and W.H. Greene. 2005 The implications on willingness to pay of respondents ignoring specific attributes. Transportation 32:203-222.

Hensher, D.A. and J.M. Rose. 2009. Simplifying choice through attribute preservation or nonattendance: Implications for willingness to pay. Transp. Res., Part E Logist. Trans. Rev. 45:583-590.

Hugie, K., C. Yue, and E. Watkins. 2012. Consumer preferences for low-input turfgrasses: A conjoint analysis. HortScience 47:1096-1101.

Kragt, M.E. 2013. Stated and inferred attribute attendance models: A comparison with environmental choice experiments. J. Agr. Econ. 64:719-736.

Krajbich, I., C. Armel, and A. Rangel. 2010. Visual fixations and the computation and comparison of value in simple choice. Nat. Neurosci. 13:1292-1298.

Lagarde, M. 2013. Investigating attribute nonattendance and its consequences in choice experiments with latent class models. Health Econ. 22:554-567. 
Leksungnoen, N., P.G. Johnson, and R.K. Kjelgren. 2012. Physiological responses of turfgrass species to drought stress under high desert conditions. HortScience 47:105-111.

Meißner, M. and R. Decker. 2010. Eye-tracking information processing in choice-based conjoint analysis. Intl. J. of Mkt. Res. 52:593-612.

Moss, J.Q., D.A. Hillock, and D.L. Martin. 2009. Managing turfgrass in the shade in Oklahoma. Division of Agricultural Sci. and Natural Resources, Oklahoma State Univ.

Patton, A. 2008. Growing turfgrass in shade. Univ. of Arkansas Coop. Ext. Serv., Inst. of Agr. and Natural Resources, FSA6140.

Poe, G.L., K.L. Giraud, and J.B. Loomis. 2005. Computational methods for measuring the difference of empirical distributions. Amer. J. Agr. Econ. 87:353-365.

Rihn, A.L. and C. Yue. 2016. Visual attention's influence on consumers' willingness-to-pay for processed food products. Agribusiness 32:314-328.

Russo, J.E. 2011. Process tracing methods for decision research: A critical review and user's guide, p. 4364. In: M. Schulte-Mecklenbeck, A. Kühberger, and R. Ranyard (eds.). Eye fixations as a process trace. Psychology Press, New York and Hove.

Scarpa, R., T.J. Gilbride, D. Campbell, and D.A. Hensher. 2009. Modelling attribute nonattendance in choice experiments for rural landscape valuation. Eur. Rev. Agr. Econ. 36:151-174.

Stier, J.C., K. Steinke, E.H. Ervin, F.R. Higginson, and P.E. McMaugh. 2013. Turfgrass benefits and issues. Turfgrass: Biol., Use, and Mgt. 56:105-145.

Swift, C.E. and A.J. Koski. 2007. Growing turf on salt-affected sites. Serv. in action; no. 7.227.

Trenholm, L.E. 2000. Low temperature damage to turf. Univ. of Florida Coop. Ext. Serv., Inst. of Food and Agr. Sci., EDIS.

USDA-NASS. 2019. Census Data Query Tool. 6 Jul 2020. <https://www.nass.usda.gov/Quick_Stats/ CDQT/chapter/1/table/39/state/US/year/2017>.

van der Laan, L.N., I.T. Hooge, D.T. De Ridder, M.A. Viergever, and P.A. Smeets. 2015. Do you like what you see? The role of first fixation and total fixation duration in consumer choice. Food Qual. Prefer. 39:46-55.

Van Loo, E.J., V. Caputo, R.M. Nayga, H.-S. Seo, B. Zhang, and W. Verbeke. 2015. Sustainability labels on coffee: Consumer preferences, willingness-to-pay and visual attention to attributes. Ecol. Econ. 118:215-225.

Vidal, L., L. Antúnez, A. Sapolinski, A. Giménez, A. Maiche, and G. Ares. 2013. Can eyetracking techniques overcome a limitation of conjoint analysis? Case study on healthfulness perception of yogurt labels. J. Sens. Stud. 28:370-380.

Yue, C., K. Hugie, and E. Watkins. 2012. Are consumers willing to pay more for low-input turfgrasses on residential lawns? Evidence from choice experiments. J. Agr. Appl. Econ. 44:549-560.

Yue, C., J. Wang, E. Watkins, S.A. Bonos, K.C. Nelson, J.A. Murphy, W.A. Meyer, and B.P. Horgan. 2017. Heterogeneous consumer preferences for turfgrass attributes in the United States and Canada. Can. J. Agr. Economics/Revue canadienne d'agroeconomie 65:347-383.

Zhao, Y., G.C. Fernandez, D.C. Bowman, and R.S. Nowak. 1994. Selection criteria for droughtresistance breeding in turfgrass. J. Amer. Soc. Hort. Sci. 119:1317-1324. 